\title{
FÓRUM
}

Artigo convidado

DOI: http://dx.doi.org/10.1590/So034-759020160602

\section{VAREJO: COMPETITIVIDADE E INOVAÇÃO}

\section{CONGRESSO LATINO-AMERICANO DE VAREJO (CLAV 2015)}

“Competitividade e Inovação" foi o tema do $8^{\circ}$ Congresso Latino-Americano de Varejo (CLAV) realizado na FGV/EAESP em 29 e 30 de outubro de 2015. Desde 2008, ano do primeiro CLAV, as características principais do congresso têm-se fortalecido: i) discussão científica de temas de varejo com implicações para o mercado; ii) reflexão sobre temas de vanguarda para o varejo; iii) interação entre profissionais de mercado e acadêmicos, seja pelo formato de painéis de executivos, como maneira de se colocar em discussão as demandas de conhecimento do mercado, seja pela submissão de artigos executivos e casos de ensino; iv) relevância não apenas aos pesquisadores e palestrantes experientes da academia, mas também àqueles que estão iniciando, com o tradicional consórcio doutoral e a banca de iniciação científica para alunos de graduação; v) internacionalização: ao longo destes anos, o CLAV tem priorizado a vinda de pesquisadores reconhecidos na academia internacional, como editores de periódicos de alto impacto no varejo, e a atração de artigos estrangeiros, com sessões de apresentação exclusivamente em inglês. Ao longo de sua história, o CLAV tem recebido apoio das três principais agências de fomento brasileiras: Capes, CNPq e FAPESP. A realização do CLAV é do GVcev (Centro de Excelência em Varejo da FGV/EAESP), o qual reúne professores, alunos dos cursos da graduação e pós-graduação da FGV/EAESP e de outras instituições de ensino/pesquisa.

Nos últimos anos, o varejo vem sofrendo mudanças expressivas no cenário internacional, o que reflete nas discussões dos profissionais e dos pesquisadores de administração. No contexto de país emergente, deve-se esperar interesse renovado ao varejo, já que esse setor é um catalizador de desenvolvimento não apenas de negócios, mas também dos aspectos sociais. Por esse motivo, o CLAV reflete o ambiente acadêmico e de negócios do Brasil e da América Latina, proporcionando aos participantes do evento melhor entendimento do varejo, com enfoque nas transições pelo qual o varejo global e nacional vem passando.

\section{COMPETITIVIDADE E INOVAÇÃO NO VAREJO}

0 crescimento nos mercados emergentes tem atraído atenção de consumidores, fabricantes de bens de consumo e varejistas (Kumar, Sunder, \& Sharma, 2015). Entretanto, o ambiente de negócios no varejo em alguns desses mercados, como o Brasil, tem apresentado momentos de fragilidade em virtude de problemas econômicos e políticos principalmente a partir de 2014. Gupta, Malhotra, Czinkota, e Foroudi (2016) sugerem a importância da conexão entre inovação e competitividade, identificando que a competitividade de uma empresa permite que seus gestores inovem nas práticas mercadológicas. Estudos e práticas para essa busca nos mercados consumidores podem impactar o resultado de empresas no varejo e potencialmente influenciar o desenvolvimento econômico no país, motivando, portanto, a escolha do tema do CLAV-2015 de "Competitividade e Inovação".

Embora exista consenso de que a inovação envolve aplicação de novas ideias que estimulam o desempenho financeiro, o termo apresenta interpretações que dependem do contexto em que ela ocorre. Os conceitos iniciais derivam da teoria econômica ou teoria das organizações e são fundamentados na lógica centrada em manufatura. Inovação na indústria de serviços, incluin- 
do o varejo, tem recebido pouca atenção na literatura (Hristov \& Reynolds, 2015). Empresas alcançam a vantagem competitiva por meio de iniciativas de inovação, que são manifestadas em novos produtos, serviços, processos ou novas abordagens com base em estratégias e atividades de marketing (Porter, 1990). Definições tradicionais descrevem o varejo como "negócio que vende produtos e serviços para consumidores finais" (Rosenberg, 1993; Levy \& Weitz, 1996, p. 419), então o varejo e o escopo de suas atividades parecem simples e muitas vezes tornam a área carente de contribuições sobre como suas organizações podem ser mais competitivas e inovar (Peterson \& Balasubramanian, 2002). Alguns autores (como Pantano, 2014; Hristov \& Reynolds, 2015) descrevem os varejistas como adotantes de tecnologias e inovação, e não desenvolvedores de novas tecnologias como ocorre em outras indústrias. $E$ a adoção se dá muitas vezes como meio de aumentar sua capacidade de compreensão de mercados e tendências futuras, em vez de prover uma experiência mais valiosa para o cliente. Ao introduzir uma nova tecnologia, o varejista sempre questiona até que ponto ela seria usada pelo consumidor ou o gestor obteria dados para prever tendências ou facilitar sua tomada de decisão. Mas, apesar disso, pesquisas com consumidores indicam a sua crescente procura de inovação no ponto de venda (Cox et al., 2016).

Apesar disso, como qualquer atividade de negócios, o varejo evolui e inova com o tempo. Avanços tecnológicos e mudanças no comportamento do consumidor, impulsionados pelos novos dispositivos e pela mídia, continuam a transformá-lo. As mudanças têm sido mais intensas com a disseminação da internet, mídias sociais e aparelhos móveis, provendo aos consumidores acesso mais fácil a informações e fontes de compras. Clientes mais jovens terão maiores expectativas de usar canais de compras on-line influenciados pelas mídias sociais (Cox et al., 2016). Varejistas têm desenvolvido aplicativos para melhorar e estender a experiência de compra desses usuários para além da loja física (Grewal, Roggeveen, Runyan, Nordfält, \& Lira, in press). Muitos consumidores têm acesso a uma variedade de ferramentas de mídia via smartphones e tablets, que lhes dão acesso instantâneo a blogs e conteúdos e informação, e podem usar aplicativos para encontrar os preços mais baixos ou descobrir o que os amigos estão comprando, tornando mais fácil a busca de opções alternativas e tornando-os mais sensiveis aos preços. Uma abordagem da gestão da inovação para o varejo, principalmente para tais clientes, consiste em envolvê-los no novo processo de desenvolvimento de produtos/serviços para melhorar o resultado final e o nível de qualidade. Por isso, muitos estudos (Greer \& Lei, 2012; Kohler et al., 2011) centram-se em estratégias na participação dos consumidores no processo de cocriação para que seu conhecimento seja aproveitado em novos produtos (Pantano, 2014), explorando novas tecnologias, principalmente por meio da internet.

Por outro lado, o crescente envelhecimento da população levará à demanda por mais conveniência e disponibilidade local dos produtos, o que implica que a demanda por loja física de varejo continua (Cox et al., 2016). Mas tal demanda pode ter características experienciais, num novo modelo, em que o ponto de venda aumenta o envolvimento do cliente, permitindo-lhe interagir com produtos e obter informação sobre a melhor maneira de usá-los. Por exemplo, numa loja de móveis, o cliente pode ser capaz de "entrar" nas dimensões de sua sala de estar e ver como o mobiliário novo fica mais bem adequado, podendo mudar virtualmente design, cores e padrões. Essa experiência na loja física, portanto, requer tecnologia e inovação.

Essa combinação de experiências on-line e na loja física remete ao termo multicanalidade. 0 tema de diversificação de canais em marketing não é novo, mas a evolução no número de canais que devem ser considerados numa estratégia varejista parece ser uma mudança disruptiva (Grewal et al., in press), ainda mais se eles forem usados pelo consumidor de maneira indistinta, originando o termo omnichannel. Com a entrada de canais mobile, smartphones e mídias sociais, e com a integração deles e de outros meios ao canal off-line, passa-se da forma multicanal para o modelo de varejo omnichannel. Diferentemente da multicanalidade, que considera apenas os canais de venda do varejo, no ambiente omnichannel, há ênfase na interação entre canais e marcas, ou seja, há interações entre comprador, marca e varejista. Esse novo modelo de negócios, portanto, tem um foco menor no canal utilizado e maior na interação entre o comprador e a marca (Verhoef, Kannan, \& Inmane, 2015). Adicionalmente, tais mudanças são impulsionadas por novos softwares a elas relacionados: aplicativos, pagamentos móveis, cupons digitais, serviços baseados em geolocalização etc. Mas, quando o varejista adiciona novos canais para o cliente, ele também precisa revisar ou adicionar novos sistemas de logística para garantir que o produto seja entregue. Inovações como o uso de carros autodirigíveis e robotização, por exemplo, já estão sendo usadas para reduzir custos de entregas e custos operacionais, quando se trabaIha com o conceito de multicanalidade (Cox et al., 2016).

Em termos de multicanalidade, há uma grande oportunidade para o varejo brasileiro, e o volume de dados já transacionados pelo e-commerce atesta isso. O Brasil é o único país da América Latina que figura entre os dez maiores mercados mundiais do e-commerce. Se, por um lado, fica claro que o shopper brasileiro está se tornando multicanal, por outro é possível dizer que hoje ele ainda não tem uma experiência completa de compra omnichannel, visto que, de modo geral, os varejistas brasileiros ainda não se adequaram a esse ambiente. Pequenos varejistas, 
por exemplo, geralmente não apresentam presença digital forte, portanto devem se desenvolver no ambiente on-line, enquanto empresas maiores têm de garantir que os consumidores recebam suas ofertas de forma padrão em todos os canais. É em época de crise que as tais oportunidades são vislumbradas em busca de garantir a competitividade atual e futura. 0 varejo formal brasileiro representa apenas $15,5 \%$ do produto interno bruto (PIB), sendo que, em países como Estados Unidos, representa 28\%. Isso significa que a maior formalização do varejo deve contribuir para o aumento da participação no PIB, com implicações para a competitividade das empresas que atuam no setor.

Sempre haverá os efeitos colaterais da inovação. Mídias sociais on-line e móveis, por exemplo, oferecem oportunidades para os varejistas se comunicarem de forma personalizada, principalmente com os jovens, mas também acarretam desafios associados a potenciais ameaças à privacidade do consumidor (Aguirre, Mahr, Grewal, Ruyter, \& Wetzels, 2015). Portanto, tais inovações requerem transparência sobre quando e como os dados do consumidor são coletados. A disseminação das práticas de personalização da comunicação faz com que os consumidores sejam mais conscientes de que as empresas coletam suas informações on-line e off-line. Isso provavelmente provoca maior ceticismo em relação ao varejista, o que pode ser problemático numa época em que há também uma crise de confiança entre consumidores e empresas.

Em se tratando de inovação no varejo, o setor também tem papel importante nas questões de sustentabilidade, em razão de seu poder econômico global e sua posição privilegiada entre oferta e demanda. Os varejistas podem influenciar tanto a produção quanto os padrões de consumo (Delai \& Takahashi, 2013). Também podem influenciar em suas cadeias de abastecimento como resultado de suas estratégias de sustentabilidade, moldando decisões e atividades, como o desenvolvimento de novos produtos, estratégias de recursos humanos, aspectos de distribuição e padrões de embalagem. No lado da demanda, os varejistas podem influenciar os consumidores no modo como eles compram, usam e descartam os produtos. Nessa perspectiva, a pesquisa em varejo tem evoluído e também buscado oferecer contribuições para a competitividade das organizações envolvidas, com potencial impacto no desenvolvimento econômico no país, principalmente com a preocupação atual sobre os problemas econômicos e políticos citados aqui. Portanto, o propósito do CLAV 2015 foi criar condições para discutir contribuições para a literatura sobre competividade e inovação no varejo, assim como para as organizações de varejo e seus consumidores, com artigos apresentados em diversas trilhas acadêmicas: estratégias varejistas, eficiência e tecnologia, fator humano nas organizações varejistas, relacionamento, parcerias e suplly chain, responsabilidade e sustentabilidade e comportamento do consumidor.

\section{FÓRUM RAE DE VAREJO - ARTIGOS}

Como já é de costume, os melhores artigos do CLAV-2015 em avaliação double blind review são considerados para publicação no Fórum RAE de Varejo. Este fórum discute assuntos relacionados ao tema “Competitividade e Inovação" e apresenta estudos que contribuem tanto para a literatura quanto para as práticas varejistas.

A relação entre competitividade e inovação contribui para que as organizações varejistas aperfeiçoem os modelos de negócio ou levam a propor novos modelos que as tornem mais lucrativas, prósperas e gerem valor aos stakeholders mesmo em momento adverso, como mencionado em relação ao Brasil. Em relatório sobre o varejo no Brasil, a Euromonitor (2016) indica um modelo de negócios no varejo que tem crescido mesmo em ambiente turbulento: o de franquias, que apresentou em 2015 aumento de $8 \%$ de faturamento e $10 \%$ no número de lojas franqueadas em relação ao ano de 2014, incluindo 131 novas marcas que adotaram o modelo em 2015. 0 artigo "Franchisor-franchisee relationship quality: Time of relationship and performance”, de Varotto e Parente (2016), analisa, com base em 342 franqueados, como o relacionamento entre franqueadores e franqueados se desenvolve ao longo do tempo e de que maneira esse processo influencia a qualidade de relação e o desempenho financeiro na questão franqueador-franqueado. Os resultados indicam que 0 tempo tem efeito moderador positivo nesse aspecto e apresentam implicações para a prática na gestão de franquias, pois os franqueadores devem buscar desenvolver iniciativas que permitam sustentar a relação depois do seu estágio inicial, chamado de honeymoon, após o primeiro ano de relacionamento, e o cuidado com o estágio crossroads, após oito anos.

A necessidade de que as organizações varejistas sejam inovadoras, produtivas e alcancem níveis satisfatórios de competitividade é mais evidente em períodos de adversidades no ambiente econômico. Conforme relatório apresentado pela Mckinsey (Donatelli, Hoefel, Resstom, \& Stul, 2016) e que foi desenvolvido com a proposta de investigar o comportamento do consumidor em época de desaceleração da economia, os consumidores no Brasil têm buscado economizar em suas compras no varejo e passam a prestar mais atenção em preços e promoções de produtos. Quando objetivam manter o consumo de suas marcas preferidas, buscam varejistas que as ofereçam com preço menor, porém, mais da metade dos consumidores que já optaram por marcas de menores preços alega que não tem intenção de voltar a consumir as marcas mais caras. Segundo a mesma pesquisa, apenas $18 \%$ dos clientes que optaram por marcas mais baratas compraram marcas próprias dos varejistas, enquanto na América Latina, em geral, o resultado 
foi de $26 \%$ e em países classificados como maduros chega a $60 \%$. Isso é explicado pela baixa representatividade das marcas próprias no Brasil. Contudo, é esperado aumento de inovações de marca própria e do seu papel no varejo brasileiro. 0 artigo “Antecedentes da intenção de compra de marcas próprias: Um estudo no mercado emergente", de Borges, Carvalho, e Miranda (2016), explora preditores da intenção de compra de marcas próprias com base na imagem da loja, no risco percebido e na atitude em relação a elas. Os resultados mostram que o risco percebido e a imagem da loja são fortes preditores da imagem da marca própria. 0 primeiro construto (risco percebido) inclui variáveis de risco de desempenho e financeiro. 0 segundo construto (imagem da loja) compreende variáveis como qualidade do produto, sortimento e atmosfera de loja. Como implicação para varejistas que gerenciam suas marcas próprias, o estudo identifica que, melhorando esses fatores mencionados, a atitude e a intenção de compra desses produtos podem ser influenciadas positivamente, o que contribui para sua competitividade.

Uma das atividades que muitas vezes executivos que atuam no varejo consideram a mais relevante para a competitividade das organizações envolve a gestão de pessoas, incluindo equipes e pessoal para dar suporte a vendas e ao atendimento ao consumidor final. Especificamente, os sistemas de incentivo e controle dos vendedores podem influenciar a satisfação dos consumidores e o desempenho de vendas da organização (Kraus, Haumann, Ahearne, \& Wieseke, 2015). No artigo "Os efeitos negativos da experiência e do controle no desempenho do vendedor", Silva, Faia, e Vieira (2016) identificam a relação entre o perfil de locomoção do vendedor, isto é, da proatividade do vendedor, e o desempenho de vendas a partir da proposta de investigação sobre os efeitos do sistema de controle por comportamento, incluindo como as organizações monitoram, controlem, avaliam e compensam os vendedores. Como resultado da pesquisa empírica com base nos dados de 138 vendedores no varejo, os autores mostram que o alto nível do sistema de controle por comportamento reduz o efeito entre a orientação para locomoção do vendedor e seu desempenho. Como implicação para o varejo, os autores sugerem que os gestores de vendedor no varejo proporcionem oportunidades para que eles expressem suas opiniões e participem de estratégias e ações de vendas. Ainda, identificam que, com o passar do tempo e de acordo com a experiência do vendedor, os gestores devem flexibilizar as normas rígidas de controle por comportamento e inserir mecanismos de controle diversos, como o sistema de controle por resultados.

Esperamos que este Fórum RAE estimule pesquisas adicionais no varejo sobre os vários tópicos aqui identificados.

\section{REFERÊNCIAS}

Aguirre, E., Mahr, D., Grewal, D., de Ruyter, K., \& Wetzels, M. (2015). Unraveling the personalization paradox: The effect of information collection and trust-building strategies on online advertisement effectiveness. Journal of Retailing, 91(1), 34-49. doi:10.1016/j.jretai.2014.09.005

Borges, L. A. da S., Carvalho, D. T., \& Miranda, C. de S. (2016). Antecedentes da intenção de compra de marcas próprias: Um estudo no mercado emergente. RAE-Revista de Administração de Empresas, 56(6), 611-625. doi:10.1590/So034-759020160604

Cox, A., Hay, G., Econometrics, C., Hogarth, T., Brown, G., Writing, G. B., \& Limmer, H. (2016). Productivity in the retail sector: Challenges and opportunities. Recuperado de http://www.employment-studies.co.uk/ system/files/resources/files/ukceso816d.pdf

Delai, I., \& Takahashi, S. (2013). Corporate sustainability in emerging markets: Insights from the practices reported by the Brazilian retailers. Journal of Cleaner Production, 47, 211-221. doi:10.1016/j.jclepro.2012.12.029

Donatelli, M., Hoefel, F., Resstom, S., \& Stul, F. (2006, jun.). Meet the new Brazilian consumer. Mckinsey Consumer Packaged Goods and Retail. Recuperado de www.mckinsey.com/industries/consumer-packaged-goods/our-insights/meet-the-new-brazilian-consumer

Euromonitor International Report. (2016, abr.). Retailing in Brazil. Recuperado de http://www.euromonitor.com/retailing-in-brazil/report

Grewal, D., Roggeveen, A. L., Runyan, R. C., Nordfält, J., \& Lira, M. E. V. (in press). Retailing in today's world: Multiple channels and other strategic decisions affecting firm performance. Journal of Retailing and Consumer Services. Recuperado de http://ac.els-cdn.com/ So969698916000023/1-S2.0-S0969698916000023-main.pdf? tid=6bd10618-a4e5-11e6-a258-0000oaabof 27 \&acdnat $=1478521774$ f85f5389cfaf648d96ob2d87eofed 58c

Grewal, D., \& Levy, M. (2009). Emerging issues in retailing research. Journal of Retailing, 85(4), 522-526. doi:10.1016/j.jretai.2009.09.007

Gupta, S., Malhotra, N. K., Czinkota, M., \& Foroudi, P. (2006). Marketing innovation: A consequence of competitiveness. Journal of Business Research, 69(12), 5671-5681. doi:10.1016/j.jbusres.2016.02.042

Hristov, L., \& Reynolds, J. (2015). Perceptions and practices of innovation in retailing: Challenges of definition and measurement. International Journal of Retail \& Distribution Management, 43(2), 126-147. doi:10.1108/ ijrdm-09-2012-0079

Kraus, F., Haumann, T., Ahearne, M., \& Wieseke, J. (2015). When sales managers and salespeople disagree in the appreciation for their firm: The phenomenon of organizational identification tension. Journal of Retailing, 91(3), 486-515. doi:10.1016/j.jretai.2015.03.001

Kumar, V., Sunder, S., \& Sharma, A. (2015). Leveraging distribution to maximize firm performance in emerging markets. Journal of Retailing, 91(4), 627-643. doi:10.1016/j.jretai.2014.08.005

Levy, M., \& Weitz, B. (1996). Essentials of retailing. Boston, EUA: Irwin McGraw-Hill.

Pantano, E. (2014). Innovation drivers in retail industry. International Journal of Information Management, 34(3), 344-350. doi:10.1016/j.ijinfomgt.2014.03.002

Peterson, R. A., \& Balasubramanian, S. (2002). Retailing in the 21st century: Reflections and prologue to research. Journal of Retailing, 78(1), 9-16. doi:10.1016/S0022-4359(01)00062-8

Porter, M. E. (1990). The Competitive Advantage of Nations. Harvard Business Review. Recuperado de https://hbr.org/

Rosenberg, J. M. (1993). Dictionary of business and management. New York, EUA: John Wiley \& Sons.

Silva, J. D., Faia, V. da S., Vieira, V. A. (2016). Os efeitos negativos da experiência e do controle no desempenho do vendedor. RAE-Revista de Administração de Empresas, 56(6), 626-640. doi:10.1590/Soo34759020160605

Varotto, L. F., \& Parente, J. G. (2016). Franchisor-franchisee relationship quality: Time of relationship and performance. RAE-Revista de Administração de Empresas, 56(6), 600-610. doi:10.1590/So034-759020160603

Verhoef, P. C., Kannan, P. K., \& Inman, J. J. (2015). From multi-channel retailing to omni-channel retailing: Introduction to the special issue on multi-channel retailing. Journal of Retailing, 91(2), 174-181. doi:10.1016/j. jretai.2015.02.005 